\title{
Globalization and GDP
}

\author{
Gordon G. Bechtel \\ Warrington College of Business, University of Florida, Gainesville, USA \\ Email: bechtel@ufl.edu
}

How to cite this paper: Bechtel, G. G. (2022). Globalization and GDP. Open Journal of Social Sciences, 10, 72-81.

https://doi.org/10.4236/jss.2022.102004

Received: December 13, 2021

Accepted: February 11, 2022

Published: February 14, 2022

Copyright $\odot 2022$ by author(s) and Scientific Research Publishing Inc. This work is licensed under the Creative Commons Attribution International License (CC BY 4.0).

http://creativecommons.org/licenses/by/4.0/

\begin{abstract}
This article discovers that the KOF Globalization Index and the GDP Index are 2-way FP causal, where FP denotes fractional polynomial. These globalization and GDP indexes return extremely strong $\mathrm{R}^{2} \mathrm{~s}$ of .98 and .99 for their respective 2-way FP fits. In view of these findings, and global GDP being one of the world's most valued assets, it is important to reveal what other global assets are FP-caused by global GDP. The finding here that KOF globalization drives global GDP with an $\mathrm{R}^{2}=.98$ reveals that the world is dependent on KOF too. In view of potential nuclear war and the actual trade-war, as well as COVID-19, inflationary, and global-warming shocks to all economies, protecting KOF's ability to continue increasing GDP now becomes a major challenge for forums of young people attempting to protect their planet. Although the findings in this article supply these forums with quantifications to make their case from the bottom up, these results are only a beginning begging for collective global action.
\end{abstract}

\section{Keywords}

Computing Regression Coefficients and Their Powers, Global Assets, Global Population Weighting, The Doomsday Clock, 1-Way-FP and 2-Way-FP

Causation, Swiss-Economic-Institute, United-Nations and World-Bank Time Series

\section{Introduction}

Britain's Prince Charles, at the G-20 Summit in Rome, railed that "The future of humanity and nature herself are now at stake." Charles added that the world is at "the last chance saloon" to save the planet (https://www.theguardian.com/environment/2021/oct/31/cop26-literally-the-las t-chance-saloon-to-save-planet-prince-charles). Greta Thunberg urged banks to halt funding climate destruction, adding "Lights are flashing red". Britain's Gordon Brown, former Chancellor of the Exchequer, then intimated that Amer- 
ica's President Biden must not repeat his Afghanistan error at COP26 in Scotland. Li Shuo, senior climate adviser with Greenpeace in Beijing, emphasized that "COP26 needs high-level support from China as well as other emitters... Like other countries China will come under pressure from summit organisers to commit to quicker emissions cuts and set a target date to reach carbon neutrality-a target set by Xi Jinping for 2060 in a surprise move last year" (Italics mine) (https://www.reuters.com/business/cop/xis-not-there-cop26-hopes-dim-chinese -leaders-likely-absence-2021-10-26/).

These alarm bells bolster the 2-way-FP causation between globalization and GDP reported in this article. Gross domestic product is the world's most important index, which every nation uses to measure the health of its economy. Therefore, the finding here that KOF globalization drives global GDP with an $\mathrm{R}^{2}$ $=.98$ reveals that the world is dependent on KOF too. In view of potential nuclear war and the actual trade-war, as well as COVID-19, inflationary, and environmental shocks to all economies, protecting KOF's ability to continue increasing GDP now becomes a major challenge for forums of young people attempting to save the planet. Although the findings in this article supply these forums with quantifications that make their case from the bottom up, the results below are only a beginning crying out for collective global action. Young people worldwide are demanding a healthy $21^{\text {st }}$ century. "Meanwhile the Doomsday Clock of the Bulletin of Atomic Scientists last January was set at two minutes to midnight. That's as close as it's been to terminal disaster since 1947" (Chomsky, 2020). Heeding Prince Charles and Noam Chomsky, we turn to two of the planet's most important indexes:

\section{The KOF Globalization Index and the GDP Index}

Economic data analysis, as well as the global media, rest upon indexes over sequential time series. Our analysis of United-Nations and World-Bank time series here overrides the basic canon of statistical inference, that there is fundamental uncertainty in all data. Neither denying nor quantifying uncertainty, we simply ignore it. This approach to sequential time series brings compelling advantages to the new data science. Probabilistic inference is replaced by parameter computation and random variables give way to real variables. This suggests further "statistical thinking and new foundational frameworks" that help sort out "the many philosophical issues data science presents..." (Davidian, 2013). This call has been echoed by the American National Science Foundation, which has "released a revised version of the solicitation 'Critical Techniques and Technologies for Advancing Foundations and Applications of Big Data Science..."' (Vogelius et al., 2015). Big data are non-sampled data "from electronic sources whose primary purpose is something other than statistical inference. [...] this type of Big Data typically comprises the universe and, by definition, can represent (nearly) the entire population [...]" (Horrigan, 2013: pp. 25-26). Daily price indexes, point-of-sale retail databases, universe data on hospitals, and corporate data exemplify non-sampled data. 
These variables mentioned by Horrigan, are measured on ratio and identity scales, which exceed interval scales in the hierarchy of scientific measurement (Stevens, 1946; Torgerson, 1958; Suppes \& Zinnes, 1963). For almost half a century interval scales have been beset with skepticism about their incremental benefits over and above ratio and identity scales already in use (Shapiro, 1972: p. 373). The problems associated with interval scaling, i.e. survey sampling, questionnaire interrogation, probabilistic inference, and significance testing, are absent with the global assets measured here in dollars, per cents, counts, cubic meters, and volume (cf. Section 6). In addition, the host of long-standing, and now acute, issues daunting micro-data collection and analysis are evaded by the fractional polynomial regressions in Stata commands (1) and (2) below. Micro data are beset by the unresolved competition between randomization-based and model-based regression (Chaudhuri \& Stenger, 2005; Opsomer, 2009). Both types of regression face problems of measurement error (Bound, Brown, \& Mathiowetz, 2001), sampling error (Thompson, 1997; Lohr, 2010; Brick \& Montaquila, 2009), unit nonresponse (Frankovic, Panagopoulos, \& Shapiro, 2009), missing data (Little \& Rubin, 2002), and variance estimation (Demnati \& Rao, 2004; Prášková \& Sen, 2009). Unit nonresponse alone threatens the entire survey industry due to public unwillingness to answer mail, telephone, internet, or face-to-face questions. The host of problems associated with survey measurement and process quality were discussed and illustrated over two decades ago (Lyberg et al., 1997). Today Bradburn laments that "[...] the challenges confronting the survey researcher are dominated by the difficulty in locating sample persons and getting them to respond at all.” (Bradburn, 2016: p. 94).

These issues with the KOF globalization Index and the GDP Index point to the theory and results in Sections 5 and 6 below. The findings in these two sections plead to the world community to advance the positive effects of KOF globalization.

\section{The KOF Index of Globalization $\kappa$}

K was developed at the Swiss Economic Institute, Zurich (Dreher, 2006; Potrafke, 2015; Gygli et al., 2019) and was inspired by Visions of Governance for the 21st Century in Cambridge, MA, USA. It was introduced in 2002, published in 2006, updated and detailed in 2008, and revisited by Savina et al. (2019). This index defines globalization as the process of creating networks of connections among actors at multi-continental distances, mediated through a variety of flows including people, information and ideas, capital and goods. Globalization is conceptualized as a process that erodes national boundaries, integrates national economies, cultures, technologies and governance and produces complex relations of mutual interdependence (http://globalization.kof.ethz.ch/).

Table 1 lists the six sub-indicators that make up $\boldsymbol{\kappa}$, whose standardization is described by the Swiss Federal Institute of Technology as follows:

Each sub-indicator is transformed to a scale of one to one hundred, where one hundred is the maximum value for a specific indicator and one is the minimum 
value. Higher values denote higher globalization and lower values denote less globalization. The data are transformed according to the percentiles of the original distribution. These percentiles constitute an identity scale; i.e. a scale whose transformation is restricted to multiplication by one.

The six sub-indicators of $\boldsymbol{\kappa}$ in Table 1 support Xi Jinping's plea to the 2021 World Economic Forum in Davos, Switzerland: "We must build an open world economy, firmly safeguard the multilateral trade system, and refrain from making discriminating and exclusive standards, rules, and systems, as well as high walls that separate trade, investment, and technology"

(https://www.euractiv.com) (cf. Section 1). This plea offers an investment-policy guide to foreign nationals, sovereign states, the United Nations, the World Bank, the International Monetary Fund, and the New Development Bank in Shanghai.

The importance of $\boldsymbol{\kappa}$ is closely linked to that of global GDP, which we consider next.

\section{Global GDP $\gamma$}

The year-by-year values of global GDP in trillions of current US\$ are reported by the World Bank (http://beta.data.worldbank.org):

History of $\gamma$. In the great depression Simon Kuznetz formulated American national accounts in terms of dollars, which evaluated different commodities in a common unit. He added up various national income sources and reported his result to the United States Senate in January, 1934 (Masood, 2016: Prologue, Chapters 2 and 3). "In 1940, six years after Simon Kuznetz had presented his national income estimates to the Senate, Keynes had written down in a table the basis for what today is the formula for GDP” (Masood, 2016: p. 26). This formula adds up three macro indicators, household expenditure, domestic savings, and government expenditure, which constitute Keynesian $\gamma$.

Importance of $\gamma$. In 1999, mindful of Simon Kuznets original accounting of distinct goods like cars and cereal boxes by their dollar values, the United States Commerce Department proclaimed the formula as the U.S. government's greatest invention of the 20th century (Masood, 2016: Introduction). The calibration of $\gamma$ 's three indicators in current US dollars for all nations signals a continuing

Table 1. Components of $\boldsymbol{\kappa}$.

\begin{tabular}{ll}
\hline Indicator & Sub-Indicators \\
\hline Actual flows in \% GDP & Trade, Foreign direct investment, stocks, Portfolio investment, Income payments to foreign nationals \\
Low Restrictions & Hidden import barriers, Mean tariff rate, Taxes on international trade, Capital account restrictions \\
Personal Contact & Telephone traffic, Transfers, Foreign population, International letters \\
Information Flows & Internet users, Television, Trade in newspapers \\
Cultural Proximity & Number of McDonalds, Number of Ikea, Trade in books \\
Political Globalization & Embassies in country, Membership in international organizations, \\
& Participation in U.N. Security Council missions, International treaties \\
\hline
\end{tabular}


American control of the global economy. In the plethora of global indexes, $\gamma$ looms as the composite most fundamental to the global economy. $\gamma$ is so basic, longstanding, and prestigious that market traders, analysts, and policy planners track it daily on worldwide television and internet. The new empirical economics is dominated by $\gamma$ 's "Making the Modern World" (Masood, 2016: Preface), it's fostering human development, and its availability in most national accounts.

Components of $\gamma$. Here we view $\gamma$ 's components, household expenditure, gross domestic savings, and government expenditure, as separate time-varying indicators (http://beta.data.worldbank.org):

Household final consumption expenditure (current US\$): "Household final consumption expenditure (formerly private consumption) is the market value of all goods and services, including durable products (such as cars, washing machines, and home computers), purchased by households. It excludes purchases of dwellings but includes imputed rent for owner-occupied dwellings. It also includes payments and fees to governments to obtain permits and licenses. Here, household consumption expenditure includes the expenditures of nonprofit institutions serving households, even when reported separately by the country. Data are in current U.S. dollars."

Gross domestic savings (current US\$): "Gross domestic savings are calculated as GDP less final consumption expenditure (total consumption). Data are in current U.S. dollars."

The World Bank's update of John Maynard Keynes final indicator, added during World War II (Keynes, 1940), is:

General government final consumption expenditure (current US\$): "General government final consumption expenditure (formerly general government consumption) includes all current government expenditures for purchases of goods and services (including compensation of employees). It also includes most expenditures on national defense and security, but excludes government military expenditures that are part of government capital formation. Data are in current U.S. dollars."

"Shortly before his death on 21 April 1946, Keynes persuaded the powers at the University of Cambridge to create a new Department of Applied Economics. [...] the Cambridge department along with Harvard University's Development Advisory Service would together [...] incubate the first set of ideas around what GDP would look like, and then help to export them to the four corners of the world" (Masood, 2016: p. 32). These ideas, which honed $\gamma$ in the last century, are now related to $\boldsymbol{\kappa}$ in a theory of causation.

\section{Fractional Polynomial Causation}

Research into cause and effect in the last century was followed by Clive Granger's 2003 Nobel Lecture, which treated nonlinearity between a time series $\mathbf{X}$ and a time series $\mathbf{Y}$. Relationships between $\mathbf{X}$ and $\mathbf{Y}$ are exhibited and discussed daily on worldwide television (cf. Aljazeera, CNBC, Shanghai Media Group, and Tai- 
pei Times). Clive Granger's timely Nobel Lecture introduced the concept of co-integration between $\mathbf{X}$ and $\mathbf{Y}$. Co-integration between time series $\mathbf{X}$ and time series $\mathbf{Y}$ exists when the patterns in $\mathbf{X}$ are approximately repeated in $\mathbf{Y}$ after some time lag. Thus, past values of $\mathbf{X}$ can be used for the prediction of future values of $\mathbf{Y}$ (https://en.wikipedia.org/wiki/Granger_causality). We leave it to the reader to decide if co-integration between $\mathbf{Y}$ and $\mathbf{X}$, or 2-way-FP regression of $\mathbf{Y}$ on $\mathrm{X}$ and $\mathrm{X}$ on $\mathrm{Y}$, is more precise, as well as more originative of new questions. We also note that a search of recent literature reveals no mention of fractional polynomial nonlinearity as a specific departure from nonlinearity (cf. Barnett et al., 2000; Kumar, 2019). This specificity, along with 1-way- and 2-way-FP causality, are defined below. Replacing $\mathbf{X}$ by $\boldsymbol{\kappa}$ and $\mathbf{Y}$ by $\boldsymbol{\gamma}$, we have

Definition 1. If fractional polynomial regressions of $\gamma$ on $\boldsymbol{\kappa}$ and $\boldsymbol{\kappa}$ on $\boldsymbol{\gamma}$ over 1991-2017 both return $\mathrm{R}^{2} \mathrm{~s} \geq .90$, then $\gamma$ and $\kappa$ 2-way-FP cause each other.

Corollary 1. If definition 1 holds, then $\kappa 1$-way-FP causes $\gamma$ and $\gamma$ 1-way-FP causes $\mathrm{k}$ over 1991-2017.

Definition 1 and corollary 1 evaluate $\mathrm{R}^{2} \mathrm{~s}$ by their nearness to one. Corollary 1 's criterion of 1-way-FP causation is especially stringent because it is restricted to just one independent variable, $\boldsymbol{\kappa}$ or $\boldsymbol{\gamma}$.

The measurement of $\boldsymbol{\kappa}$ and $\boldsymbol{\gamma}$ is provided by:

Definition 2. The Swiss Economic Institute computes $\boldsymbol{\kappa}$ as the average of its De facto and De jure Globalization Indexes, which are each measured as a percent.

Definition 3. The World Bank computes $\gamma$ in trillions of current US\$.

Table 2 lists the United Nation's and World Bank's measurements of 20 global assets $\mathbf{A}, \ldots, \mathrm{T}$.

\section{Results}

The criterion of 2-way-FP causation in definition 1 is confirmed by $\mathrm{R}^{2}=.98$ when $\gamma$ is FP regressed on $\boldsymbol{\kappa}$ and $\mathrm{R}^{2}=.99$ when $\boldsymbol{\kappa}$ is FP regressed on $\gamma$. Corollary 1 follows; i.e., $\boldsymbol{\kappa} 1$-way-FP causes $\gamma$ and $\boldsymbol{\gamma} 1$-way-FP causes $\boldsymbol{\kappa}$. These results are delivered by the following two 1-way FP regressions in Stata syntax.

fracpoly reg $\gamma \boldsymbol{\kappa}$ [iweight $=$ GlobalPopulation], adjust( $\kappa$ :mean) degree(1) noscaling (1) fracpoly reg $\kappa \boldsymbol{\gamma}$ [iweight $=$ GlobalPopulation], adjust $(\boldsymbol{\gamma}$ :mean) degree(1) noscaling (2)

The qualifier [iweight $=$ GlobalPopulation] denotes an importance weight assigned to the global population for $\kappa^{\prime}$ 's and $\gamma^{\prime}$ 's yearly values in $1991 \ldots 2017$. The degree (1) option maintains $\kappa^{\prime}$ 's 1-way-FP causation of $\gamma$ and $\gamma$ 's 1-way-FP causation of $\mathbf{\kappa}$; i.e. only single independent variables are allowed by the degree (1) option. These options for fractional polynomial regression are detailed in StataCorp (2011).

Table 3 shows that fractional polynomial regressions of time series A, B, .., T on $\gamma$ deliver 1-way-FP causation for $50 \%$ of the 20 global assets studied here (cf. Royston \& Altman, 1994). These global assets are measured in dollars, per cents, counts, cubic meters, and volume on a 27 (years) $\times 22$ (global assets) spreadsheet 
(cf. Table 2).

Stata commands (1) and (2) also produce the functions

$$
\begin{gathered}
\mathbf{A}=\mathrm{f}(\boldsymbol{\kappa})=.893 \\
\mathbf{A}=\mathrm{f}(\boldsymbol{\gamma})=-.555^{\star} \gamma^{-.5}+.979
\end{gathered}
$$

Function (3) shows that the 1-way-FP regression of global asset $\mathbf{A}$ on $\boldsymbol{\kappa}$ produces the mean of A's values over 1991-2017. Function (4) of $\mathbf{A}$ on $\boldsymbol{\gamma}$ illustrates the other 19 functions of $\gamma$, each of which have different forms.

It is important to note that the $\mathrm{R}^{2} \mathrm{~s}$ in Table 3 are invariant with respect to the units in which $\gamma, \mathbf{A}, \mathbf{B}, \ldots \mathrm{T}$ are calibrated.

Table 2. Measurements of global assets.

$\gamma$ : Global GDP (trillions of current US\$)

к: KOF Globalization Index (\%)

A: Human Development Index (\%)

B: Stocks traded, total value (\% of GDP)

C: Air transport, registered carrier departures worldwide (count)

D: Fixed telephone subscriptions per 100 people (count)

E: Mobil cellular subscriptions per 100 people (count)

F: Renewable internal freshwater resources per capita (cubic meters)

G: Water per capata (volume)

H: Non-Poverty headcount ratio at \$1.90 a day 2011 PPP (\% of population)

I: Market capitalization of listed domestic companies (current US\$)

J: Merchandise exports (currentUS\$)

K: Merchandise imports (currentUS\$)

L: Merchandise trade (\% of GDP)

M: Ores and metals exports (\% of Merchandise exports)

$\mathrm{N}$ : Non-military expenditure (\% of GDP)

O: Patent applications, nonresidents (count)

P: Patent applications, residents (count)

Q: Trademark applications, direct nonresident (count)

R: Trademark applications, direct resident (count)

S: Exports of goods and services (\% of GDP)

$\mathrm{T}$ : Imports of goods and services (\% of GDP)

Table 3. 1-way-FP regression $\mathrm{R}^{2}$ s for time series $\mathrm{A}, \mathrm{B}, \ldots \mathrm{T}$ on $\gamma$.

\begin{tabular}{llllllllllllllllllll}
\hline $\mathrm{A}$ & .98 & $\mathrm{~B}$ & .57 & $\mathrm{C}$ & .07 & $\mathrm{D}$ & .41 & $\mathrm{E}$ & .99 & $\mathrm{~F}$ & .96 & $\mathrm{G}$ & .96 & $\mathrm{H}$ & .98 & $\mathrm{I}$ & .87 & $\mathrm{~J}$ & .98 \\
$\mathrm{~K}$ & .98 & $\mathrm{~L}$ & .87 & $\mathrm{M}$ & .22 & $\mathrm{~N}$ & .29 & $\mathrm{O}$ & .96 & $\mathrm{P}$ & .89 & $\mathrm{Q}$ & .82 & $\mathrm{R}$ & .81 & $\mathrm{~S}$ & .92 & $\mathrm{~T}$ & .92
\end{tabular}




\section{Conclusion}

Section 6 shows that $\kappa$ and $\gamma$ are 2-way-FP causal, with extremely strong $\mathrm{R}^{2} \mathrm{~s}$ of .98 and .99. Moreover, FP regressions (1) and (2) suggest that this 2-way-FP causality of $\boldsymbol{\kappa}$ and $\boldsymbol{\gamma}$ is more precise, as well as more originative of new questions, than Granger co-integration between our $\boldsymbol{\kappa}$ and $\gamma$ time series. Finally, $\gamma$ is the world's most important economic index, which every nation uses to measure the health of its economy. Therefore, the finding here that $\kappa$ drives $\gamma$ with an $\mathrm{R}^{2}$ $=.98$ reveals that the world is dependent on $\boldsymbol{\kappa}$ too. In view of possible nuclear war, the actual trade-war, COVID-19, inflationary, global warming, and the undermining of democracy, protecting $\kappa$ 's ability to continue increasing $\gamma$ now becomes a major challenge facing the international community (cf. Chomsky, 2020). Although the findings in Section 6 help further this mission, these results are only a beginning cry to the global community to, in Prince Charles words, save the planet.

\section{Acknowledgements}

This article is dedicated to the memory of the author's best critic, Maria Cohn Bechtel. The author thanks Timothy Bechtel for contributing to the milieu for globalization and GDP, Dr. Bethany Bechtel for her insistence on monitoring globalization and GDP over time, and Aryil Bechtel for his suggestion that GDP can be parsimoniously predicted by the KOF Index only. The author appreciates the reviewer's suggestions, which have improved this work, and Alice Yao's management of this article.

\section{Conflicts of Interest}

The author declares no conflicts of interest regarding the publication of this paper.

\section{References}

Barnett, W. A., Hendry, D. F., Hylleberg, S., Terasvirta, T., Tjøstheim, D., \& Wurtz, A. (2000). Nonlinear Econometric Modelling in Time Series Analysis. Cambridge University Press.

Bound, J., Brown, C., \& Mathiowetz, N. (2001). Measurement Error in Survey Data. In J. J. Heckman, \& E. Leamer (Eds.), Handbook of Econometrics (Volume 5, pp. 3705-3843). Elsevier Science. https://doi.org/10.1016/S1573-4412(01)05012-7

Bradburn, N. (2016). Surveys as Social Interactions. Journal of Survey Statistics and Methodology, 4, 94-109. https://doi.org/10.1093/jssam/smv037

Brick, J., \& Montaquila, J. M. (2009). Nonresponse and Weighting. In D. Pfeffermann, \& C. R. Rao (Eds.), Handbook of Statistics (Sample Surveys: Design, Methods and Applications)(Volume 29A, pp. 163-185). Elsevier.

https://doi.org/10.1016/S0169-7161(08)00008-4

Chaudhuri, A., \& Stenger, H. (2005). Survey Sampling: Theory and Methods (2nd ed.). CRC Press. https://doi.org/10.1201/9781420028638

Chomsky, N. (2020). Internationalism or Extinction. Routledge. 
https://doi.org/10.4324/9781003001034

Davidian, M. (2013). Aren't We Data Science? Amstat News, July, 3-5.

Demnati, A., \& Rao, J. N. K. (2004). Linearization Variance Estimators for Survey Data. Survey Methodology, 30, 17-26.

Dreher, A. (2006). Does Globalization Affect Growth? Evidence from a New Index of Globalization. Applied Economics, 38, 1091-1110. https://doi.org/10.1080/00036840500392078

Frankovic, K. A., Panagopoulos, C., \& Shapiro, R. Y. (2009). Opinion and Election Polls. In Handbook of Statistics (Sample Surveys: Design, Methods and Applications) (pp. 567-595). Elsevier. https://doi.org/10.1016/S0169-7161(08)00022-9

Gygli, S., Haelg, F., Potrafke, N., \& Sturm, J.-E. (2019). The KOF Globalisation Index-Revisited. Review of International Organizations, 14, 543-574. https://doi.org/10.1007/s11558-019-09344-2

Horrigan, M. W. (2013). Big Data: A Perspective from the BLS. Amstat News, January, 25-27.

Keynes, J. M. (1940). How to Pay for the War. Macmillan.

Kumar, U. D. (2019). Business Analytics: The Science of Data Driven Decision Making. Wiley India Pvt. Ltd.

Little, R. J. A., \& Rubin, D. B. (2002). Statistical Analysis with Missing Data. Wiley and Sons. https://doi.org/10.1002/9781119013563

Lohr, S. L. (2010). Sampling: Design and Analysis (2nd ed.). Brooks/Cole.

Lyberg, L., Biemer, P., Collins, M., de Leeuw, E., Dippo, C., Schwarz, N., \& Trewin, D. (1997). Survey Measurement and Process Quality. Wiley and Sons. https://doi.org/10.1002/9781118490013

Masood, E. (2016). The Great Invention: The Story of GDP and the Making and Unmaking of the Modern World. Pegasus Books Ltd.

Opsomer, J. D. (2009). Introduction to Part 4: Alternative Approaches to Inference from Survey Data. In D. Pfeffermann, \& C. R. Rao (Eds.), Handbook of Statistics (Sample Surveys: Inference and Analysis (Volume 29B, pp. 3-9). Elsevier. https://doi.org/10.1016/S0169-7161(09)70040-9

Potrafke, N. (2015). The Evidence on Globalization. The World Economy, 38, 509-552. https://doi.org/10.1111/twec.12174

Prášková, Z., \& Sen, P. K. (2009). Asymptotics in Finite Population Sampling. In D. Pfeffermann, \& C. R. Rao (Eds.), Handbook of Statistics (Sample Surveys: Inference and Analysis) (Volume 29B, pp. 489-522). Elsevier.

https://doi.org/10.1016/S0169-7161(09)00240-5

Royston, P., \& Altman, D. J. (1994). Regression Using Fractional Polynomials of Continuous Covariates: Parsimonious Parametric Modeling (with Discussion). Applied Statistics, 43, 429-467. https://doi.org/10.2307/2986270

Savina, G., Haelg, F., Potrafke, N., \& Sturm, J.-E. (2019). The KOF Globalisation Index-Revisited. Review of International Organizations, 14, 543-574.

https://doi.org/10.1007/s11558-019-09344-2

Shapiro, H. (1972). The Index of Consumer Sentiment and Economic Forecasting: A Reappraisal. In B. Strumpel, J. N. Morgan, \& E. Zahn (Eds.), Human Behavior in Economic Affairs (p. 373). Jossey-Bass.

StataCorp (2011). Stata Statistical Software, Release 12. StataCorp LP.

Stevens, S. S. (1946). On the Theory of Scales of Measurement. Science, 103, 677-680. 
https://doi.org/10.1126/science.103.2684.677

Suppes, P., \& Zinnes, J. L. (1963). Basic Measurement Theory. In R. R. Bush, R. D. Luce, \& E. Galanter (Eds.), Handbook of Mathematical Psychology (Volume I, pp. 1-76). John Wiley \& Sons.

Thompson, M. E. (1997). Theory of Sample Surveys. Chapman and Hall. https://doi.org/10.1007/978-1-4899-2885-6

Torgerson, W. S. (1958). Theory and Methods of Scaling. John Wiley \& Sons.

Vogelius, M., Kannan, N., \& Huo, X. (2015). NSF Big Data Funding Opportunity for the Statistics Community. Amstat News. 